\title{
GESTIÓN DEL CONOCIMIENTO Y DEL CAPITAL INTELECTUAL: \\ UNA FORMA DE MIGRAR HACIA EMPRESAS INNOVADORAS, PRODUCTIVAS Y COMPETITIVAS
}

Luz Victoria Díaz*

\section{RESUMEN}

RESUMEN

Toda empresa, ya sea que haya emprendido o no una iniciativa de gestión de conocimiento, tiene entre sus pertenencias una serie de bienes, con mayor o menor componente material e inmaterial, pero de reconocida importancia estratégica: conocimiento del mercado; capacidades y recursos para el desarrollo de productos; equipo humano con determinadas habilidades, actitudes, experiencias, conocimientos; reglas y políticas de trabajo; sistemas de información y bases de datos específicas; relaciones con otras organizaciones y entidades. Estos son ejemplos de aquellos bienes de difícil imitación pero que hacen parte del capital que permite a las organizaciones diferenciarse $y$ construir ventajas competitivas. La literatura internacional coincide en denominar a todos estos bienes capital intelectual y uno de los retos de las organizaciones es hacer que éste se traduzca en factores que producen beneficios tangibles.

El artículo presenta el esquema general del Modelo de Modernización de Gestión Organizacional en su versión 2 MMGOV2 que propone la Universidad EAN a través del Grupo de Investigaciones GPYMEs- para analizar las trayectorias de migración a empresas innovadoras, productivas y competitivas, mediante la utilización de prácticas de gestión del conocimiento, gestión del capital intelectual y gestión por procesos.

\section{Palabras Clave}

Gestión de conocimiento, capital intelectual, capital humano, capital estructural, capital relacional, gestión por procesos, conocimiento potencial, innovación, productividad, competitividad.

\section{INTRODUCCIÓN}

$\mathbf{E}$ los componentes y la dinámica que promueve el Proceso «K» (de Gestión de Conocimiento y Capital Intelectual), considerado como el proceso mediante el cual se facilita la administración de los flujos de conocimiento y se transforma el que proviene de las diferentes fuentes de conocimiento, internas y externas a la organización, que configuran el potencial de conocimiento de la misma. El procesamiento y transformación de este produce las innovaciones, que gracias a los valores agregados que representan para los diferentes «stakeholders», satisfacen y superan sus expectativas. Este ciclo, a su vez, enriquece las capacidades de la organización, haciéndola más productiva y competitiva, dado que incrementa su capital intelectual y contribuye al desarrollo de capacidades de aprendizaje y creatividad en la organización, debido al conocimiento internalizado que motiva la creación de nuevo conocimiento. Esta dinámica caracteriza el ciclo virtuoso que promueve el modelo.

\footnotetext{
1 Ingeniera electrónica, Pontificia Universidad Javeriana. Especialista en Gerencia de Empresas de Telecomunicaciones, Universidad de los Andes. Actualmente Investigadora del Grupo PyMES de la Universidad EAN.Colombia.
} 
Entre los retos organizacionales del siglo XXI, ha cobrado especial importancia la habilidad de gerenciar el conocimiento y traducirlo en empresas más productivas y competitivas gracias a su capacidad de innovar. ¿Y de qué conocimiento estamos hablando? De aquel que facilita a las empresas la toma de decisiones y la toma de conciencia clara de las implicaciones que se desprenden de éstas, comprendiendo y eligiendo el modo más conveniente de actuación ante las diferentes variables que afectan el mercado e inciden en el ciclo de vida de sus productos o servicios, para orientar las innovaciones que permiten mantener ofertas renovadas y atractivas.

De este modo, el conocimiento requerido por cada organización se encuentra en diferentes fuentes, tales como:

- Las personas, a través de aspectos como sus valores, capacidades, experiencias.

- La organización a través de su «know how», la experiencia existente en sus rutinas, sus sistemas, sus procesos, su cultura, su estilo de dirección.

- La tecnología, como sistemas de información que facilitan la creación de conocimiento mejorado o extendido a partir del conocimiento creado por las personas.

- El entorno o mercado, donde se producen cambios y retos permanentes, tales como, en el campo de acción del negocio, en la cadena de producción donde se actúa, en la conformación de diferentes posibles sistemas de valor para ofrecer productos y servicios nuevos y/o mejorados.

Para cada una de estas fuentes de manera coordinada, el conocimiento debe hacerse explícito y ser administrado, transformado y enriquecido para su uso, con fines que generen

\section{Abstract}

Any company, which has paved the way for knowledge management or not, has a set of material or intangible things which really has a pertinent strategic importance: market knowledge; capacities and resources to develop all its products; a human talented group with attitudes, experiences, and the like; work rules and policies; information systems and specific data bases; relationship with other companies.

These are some of the most important things companies have and which can not be imitated, but they make up part of the capital that allows them to differentiate from others, having competitive advantages.

The international literature defines all these company belongings Intellectual capital, making it one of the company challenges and turning them into company tangible goods. Finally, this article shows a general framework of the Modernization model of Organizational Management in its 2 MMGOV2, which is clearly proposed by the EAN GPyMEs research group aiming at analyzing the steps made to become innovative, productive and competitive companies through practical experiences in knowledge management, intellectual capital management and process management.

\section{KEY WORDS}

Knowledge management, intellectual capital, human capital, structural capital, relational capital, process management, potential management, innovation, productivity, competitivity. 
valor a las organizaciones. Para ello, no sólo es necesario evaluar y re pensar los negocios actuales sino identificar los ramos que la empresa debería considerar en el futuro. Las organizaciones necesitan criterios para modificar (crear, mantener o incluso desaparecer) cada uno de sus productos ylo servicios en el momento oportuno y también para mejorar sus procesos (gerenciales, administrativos, de producción y apoyo), lo cual es lo que les permite producir y competir más y mejor.

Identificar las oportunidades de crecer requiere conocimiento. Una mirada a la oferta actual de las empresas exige respuesta a diversas situaciones: ¿cómo logar mayor penetración del mercado y vender más a los clientes actuales sin cambiar de productos? ¿Recortando precios, aumentando publicidad, utilizando nuevos canales de distribución? ¿Cómo identificar y desarrollar nuevos mercados para los productos y servicios actuales? ¿Qué nuevos criterios de segmentación y selección de nichos utilizar? ¿Ofrecer a los clientes actuales nuevos productos o servicios a partir de los existentes, pero modificados de algún modo que motive su mayor consumo? ¿Iniciar o comprar negocios fuera de lo que constituye para las organizaciones sus productos y mercados actuales?

Las anteriores preguntas surgen simplemente de analizar la oferta actual. Si se da una mirada más amplia, con respecto a los competidores, surgen preguntas adicionales, tales como: ¿Quiénes son nuestros competidores? ¿Qué objetivos y estrategias tienen? ¿Cuáles son sus puntos débiles y fuertes? ¿Cómo reaccionarán ante las diferentes estrategias competitivas que la organización pueda definir y aplicar?

Pasando a los proveedores, por ejemplo, maximizar la eficiencia de la cadena de suministro depende de la aplicación de conocimiento en diversas áreas, tales como: seleccionar adecuadamente el origen de los insumos (materiales e inmateriales); establecer los mejores requisitos, criterios y condiciones de producción y elegir las alternativas de distribución más ágiles.

Así mismo, el desarrollo de productos demanda conocimiento de los clientes, no solo de los actuales, sino también de los potenciales. El conocimiento de los clientes debe conducir a promover las acciones que permiten a las organizaciones cada vez una mayor aproximación a los mismos: desde la etapa de creación de conciencia sobre lo que se ofrece, hacia motivar la exploración de la propuesta que conduzca a lograr el compromiso, con una experiencia que satisfaga y supere sus expectativas. Una vez los clientes alcanzan el compromiso, la firma está en posición de observar su comportamiento y patrones y determinar cuáles nutrir y con cuáles asumir otras tácticas, entre ellas, redireccionar los esfuerzos o servir a menores costos. Las firmas deben segmentar sus clientes más valiosos y menos valiosos con base en los ingresos que generan y el significado estratégico que representan, lo que también implica tener conocimiento.

El desarrollo de productos también requiere el análisis de la disponibilidad de nuevas tecnologías y su impacto en las capacidades y competitividad de la empresa, de los nuevos requisitos para una actividad de mercadeo efectiva que interprete estos cambios. $Y$ el escenario se vuelve más exigente ante la necesidad de atender, de manera personalizada y a la medida, las necesidades y oportunidades que están asociadas con la realidad de cada uno de los clientes.

Tener criterios de decisión ante estos aspectos, que no son estáticos, exige a las empresas estar en el lugar correcto, en el momento correcto, con el conocimiento correcto. Desarrollar y tener este conocimiento, 
pasa a ser parte de los activos de las organizaciones, a través de los cuales se pueden crear ventajas competitivas.

La Universidad EAN, a través del Grupo de Investigación GPYMEs, ha asumido el reto de asimilar, adaptar y generar una propuesta de gestión que aplique y aproveche estos conceptos según el contexto de empresas colombianas; como resultado, ha diseñado un Modelo de Modernización de la Gestión Organizacional orientado a la innovación, denominado MMGOV2. El Modelo facilita a las empresas la adopción de mejores prácticas de Gestión de Conocimiento y de Gestión de Procesos que utilizan, con el fin de que transformen y generen conocimiento para la creación o invención de lo que cada una requiera como prioridad en su trayectoria de modernización: desde la creación o mejora de un producto o servicio que impacte positivamente el mercado, hasta la simplificación y optimización de un determinado proceso. De este modo, la aplicación del modelo acompaña a las empresas para que sean más productivas y competitivas.

\section{El MODELO CONCEPTUAL PARA LA GESTIÓN DEL CONOCIMIENTO Y DEL CAPITAL INTELECTUAL}

\begin{abstract}
C
omprendiendo a qué conocimiento nos referimos y reconociendo la necesidad de gestionarlo, se acepta que el reto para las organizaciones del siglo XXI consiste en saber sobre sus negocios para permanecer y crecer y no únicamente hacer negocios para sostener la dinámica a la que obligan los ejercicios ocasionales de planeación y la fijación de metas presupuestales. Esta sencilla pero práctica definición, coincide con lo que es el conocimiento: la diferencia entre el hacer y el saber del negocio, el factor que orienta a las empresas hacia la permanente generación de propuestas innovadoras que generan valor para las compañías y aumentan su productividad y competitividad.
\end{abstract}

Bajo esta perspectiva, la Gestión de Conocimiento es el desarrollo en una organización de las capacidades y actividades que le permite diseñar nuevos productos y mejorar los existentes, así como modificar y mejorar sus procesos (administrativos y de producción); es el saber hacer en contexto que hoy es global. Para la toma de decisiones en las diferentes áreas y momentos de las empresas, el conocimiento debe ser adecuada y oportunamente identificado, asimilado y adaptado para, sobre esa base, sistematizarlo (sintetizarlo, almacenarlo y ponerlo a disposición para su acceso) y facilitar la creación de nuevo conocimiento, útil a la competitividad y productividad de la empresa. El resultado esperado de este proceso es el logro de propuestas innovadoras: nuevos productos, nuevos servicios, nuevos procesos, nuevas posibilidades y oportunidades. Estas labores constituyen retos de la Gerencia, tan importantes como los tradicionales intereses de disponer de la mejor planta, equipos, maquinaria, tecnología y, en general, bienes tangibles. Los activos intangibles, tales como sus procesos, la conformación y mantenimiento de bases de datos especializadas, la capacidad de aprendizaje y de creación de iniciativas de sus recursos humanos, entre otros, son considerados los «activos o bienes de conocimiento»; identificarlos, nutrirlos, aplicarlos, 
protegerlos, refrescarlos son factores de éxito para las organizaciones innovadoras.

De manera paralela a la anterior reflexión sobre el porqué y el para qué de la gestión del conocimiento en las organizaciones, la gestión de procesos que propone el modelo, surge ante la necesidad empresarial de rescatar el valor de los procesos empresariales como una fuente de ventaja competitiva, operando a través de procesos cada vez más eficientes y eficaces, con fines tales como optimizar el esquema de costos, mejorar constantemente la calidad de la producción, presentar productos y/o servicios nuevos que garanticen permanencia y crecimiento en el mercado o incluso todas las razones anteriores.

El enfoque por procesos permite a una organización establecer un sistema de estrecha interacción y control entre diferentes niveles -generales y específicos- de objetivos y estrategias con la ejecución y optimización de procesos particulares, generando un impacto positivo en el desempeño organizacional. Con este enfoque, se busca que las empresas no se concentren únicamente en términos de diseño, automatización y control de procesos individuales, sino en cómo un proceso particular conduce a la innovación, genera rentabilidad, impacta los objetivos nucleares del negocio, permitiendo la permanente integración de la estrategia del negocio con su operación.

De este modo, la adecuada gestión de los procesos que facilitan el flujo de conocimiento para el desarrollo de las actividades cruciales de los negocios y la calidad del conocimiento que se transforma y enriquece son, en gran medida, factores de éxito para las organizaciones en el mercado competitivo de hoy y constituyen la esencia del modelo MMGOV2.

El modelo propuesto por el grupo GPYMEs de la Universidad EAN destaca como punto de partida y de llegada la misión que tienen las organizaciones de satisfacer y superar las expectativas y exigencias de sus diferentes grupos de interés o "stakeholders»", agregando valor para los mismos. Con este propósito, se rescata la importancia de los procesos y de la gestión del conocimiento que fluye en los mismos. Como se mencionó en la introducción, el enfoque por procesos es de especial interés dado su impacto en la optimización de costos, incremento de productividad, facilidad para el control y repetición de actividades y, en general, por el soporte que ofrece para una organización más ágil. La propuesta consiste en concebir las actividades organizacionales, articuladas y alineadas en cuatro grupos de procesos macro generales: proceso de liderazgo corporativo, proceso de soporte, proceso nuclear de negocio y proceso de gestión de conocimiento y capital intelectual, que hemos denominado proceso «K» por ser la inicial de su expresión en inglés («Knowledge»).

Por otro lado, reconociendo que el resultado tangible que da sentido a una iniciativa de gestión de conocimiento es la innovación en un contexto de alta productividad y competitividad, el modelo enfatiza la importancia del flujo de conocimiento entre los diferentes procesos organizacionales, para dirigir los esfuerzos empresariales hacia innovaciones. Dichas innovaciones deberán ir acompañadas de la respectiva factibilidad técnica, económica y de mercado

\footnotetext{
2 «Stakeholders» son los grupos de interés internos y externos que tienen relación directa o indirecta con las actividades y los resultados de una empresa. Esta interrelación incluye valores, expectativas, exigencias, compromisos, negocios, que permite que la organización establezca acción de doble vía que lleven a satisfacer las necesidades de los involucrados y que sean un mecanismo que apalanque el crecimiento de la organización». (GPYMES, 2006).
} 
y estar traducidas en rentabilidad, gracias a que las organizaciones producen con reconocida calidad y compiten con ventajas sostenibles a largo plazo. Esto es, ventajas difíciles de imitar, superiores a la competencia, aplicables a múltiples situaciones, que caracterizan a organizaciones tan atentas y tan ágiles, que siempre sean capaces de diseñar y materializar una ventaja, con la flexibilidad que exige la adaptación a los diferentes cambios que ocurren en el entorno inmediato o externo y con el uso de todo su potencial para motivar cambios a favor del mercado.

La innovación aquí sugerida se dará, por lo tanto, en dos niveles: mejora o creación de productos y/o servicios a través del proceso nuclear de negocio y mejora en procesos propiamente, que aplica para los procesos generales restantes del modelo de liderazgo corporativo y de soporte.

FIGURA 1. El modelo conceptual para la gestión del conocimiento (K) y del capital intelectual

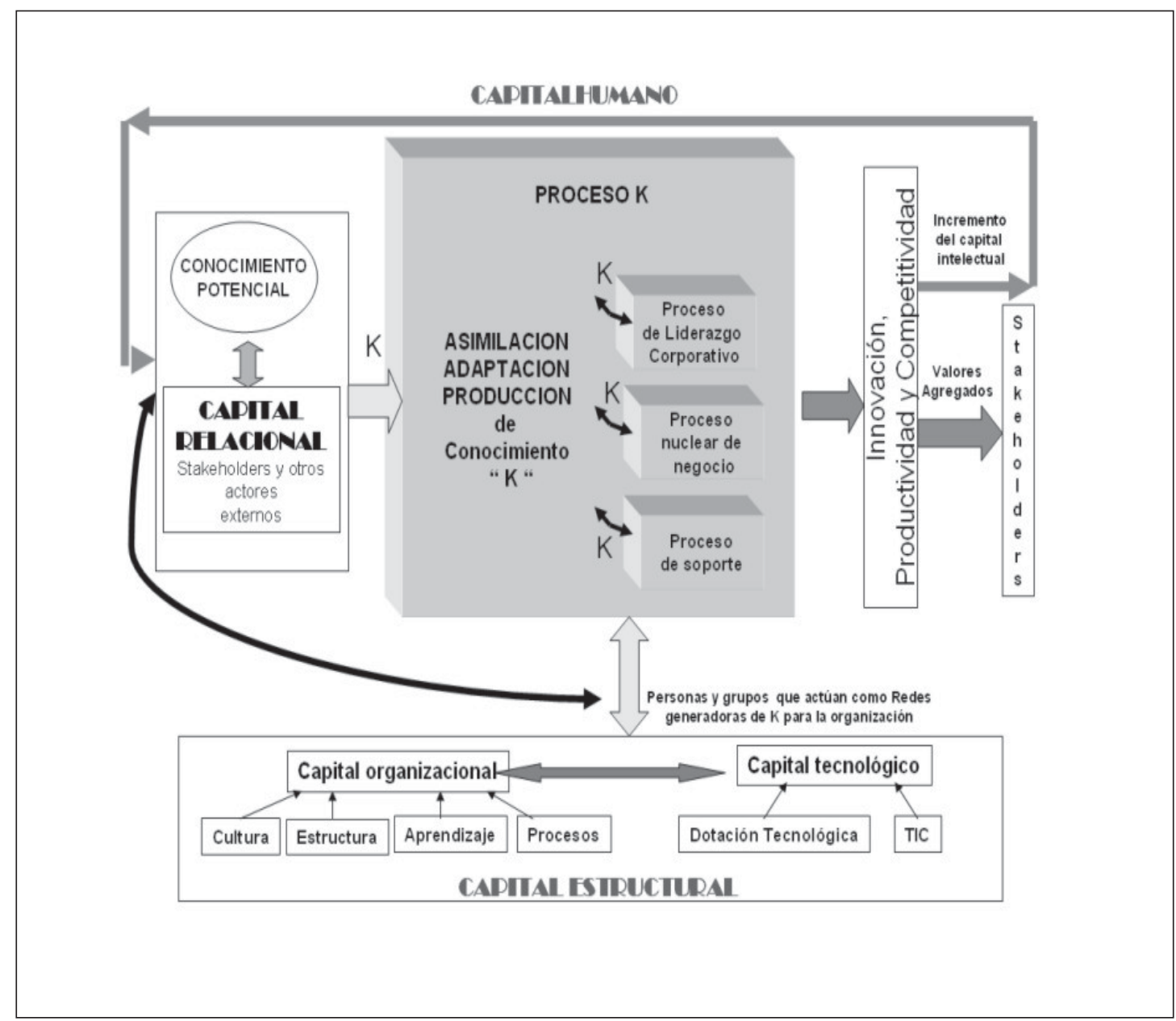

Fuente: Construcción colectiva. Vicerrectoría de Investigaciones. Grupo GPyMES, Universidad EAN 
Como lo indica la Figura 1, se considera el conocimiento $(K)$ como el insumo y a la vez el producto de particular interés, ya que constituye en sí mismo el elemento que articula los diferentes componentes del modelo. Su adecuado procesamiento y administración produce innovaciones que al incrementar la productividad y competitividad ${ }^{3}$ de la organización, conducen a la satisfacción de los intereses de los «stakeholders», donde el cliente final es de mayor importancia. Este proceso innovador produce también, como resultado, lo que se ha representado en la gráfica como incremento del «capital intelectual», generando un lazo de realimentación que constituye un ciclo virtuoso para la organización.

Bajo este esquema, a continuación se describen las principales características y orientación de los elementos del modelo, cada uno de los cuales serán tratados de manera profunda en los respectivos capítulos que conforman el marco conceptual del MMGOV2 y que serán objeto de posteriores publicaciones.

\subsection{Capital intelectual: Capital HUMANO + CAPITAL RELACIONAL + CAPITAL ESTRUCTURAL}

Toda empresa, ya sea que haya emprendido o no una iniciativa de gestión de conocimiento, tiene entre sus pertenencias una serie de bienes, con mayor o menor componente material e inmaterial, pero de reconocida importancia estratégica: conocimiento del mercado; capacidades y recursos para el desarrollo de productos; equipo humano con determinadas habilidades, actitudes, experiencias, conocimientos; reglas y políticas de trabajo; sistemas de información y bases de datos específicas; relaciones con otras organizaciones y entidades. Estos son ejemplos de aquellos bienes, de difícil imitación pero que hacen parte del capital que permite a las organizaciones diferenciarse y construir ventajas competitivas.

La literatura internacional coincide en denominar a todos estos bienes como «capital intelectual» ${ }^{4}$ y uno de los retos de las organizaciones es hacer que este capital se traduzca en factores que producen beneficios tangibles. El modelo sugerido identifica al capital intelectual con los siguientes tres componentes:

\subsubsection{Capital humano}

Representado en las actitudes, aptitudes, experiencias y modelos mentales que conducen a las personas y equipos de personas a interpretar y utilizar datos e información, relacionados con los productos, servicios, procesos, mercados y clientes involucrados en el negocio al que pertenecen. Lo anterior, con el fin de

\footnotetext{
3 La productividad describe la relación entre la «salida» de un proceso y los recursos involucrados en la generación de esta salida. Esto invita a la simplificación de procesos y reducción de costos. La competitividad representa la habilidad de una empresa para competir en un sector por el uso de su capacidad de diferenciación de productos y servicios, lo que se asocia también con la reducción de costos y la capacidad de innovación.

${ }^{4}$ La interpretación del capital intelectual que sugiere el modelo se nutre de la experiencia y conocimientos propios del grupo GPYMEs, así como de las reflexiones que al respecto se derivan de otros modelos reconocidos internacionalmente para la medición y gestión del conocimiento, tales como el Modelo»Intellectus» y el Modelo «Meritium», entre otros. Intellectus es un Modelo desarrollado por el Instituto Universitario de Administración de Empresas de la Universidad Autónoma de Madrid, socializado dentro del Foro del Conocimiento «Intellectus» sobre Sociedad del Conocimiento, año 2002. MERITUM («Measuring Intangibles To Understand and improve innovation Management») se inició como un proyecto de investigación internacional financiado por el programa TSER de la Unión Europea. El equipo estaba formado por grupos de investigación de España (país coordinador), Francia, Suecia, Noruega, Finlandia y Dinamarca. Entre 1998 y el 2000, Meritum llevó a cabo numerosos estudios de casos de empresas europeas que permitieron desarrollar un modelo genérico de análisis de los de una organización. Para más información ver: http:/ /www.uam.es/meritum
} 
generar conocimiento materializado en nuevas y mejores propuestas que representen mayor riqueza para las organizaciones. El capital humano hace referencia a las personas y a aspectos intrínsecos de las mismas, tales como, el conocimiento que poseen y crean, la experiencia acumulada y la capacidad de aprendizaje, la motivación e identidad con su ejercicio profesional, la habilidad de razonamiento y de toma de decisiones, entre otros. Incluye el conocimiento explícito o tácito útil para la empresa, así como su capacidad para regenerarlo, es decir, su capacidad para aprender ${ }^{5}$.

\subsubsection{Capital relacional}

Representado en la dinámica de las personas y grupos de personas de la organización, que se relacionan entre sí, así como con los diferentes «stakeholders» y otros actores del entorno, consolidando conocimiento y redes de conocimiento útiles a la organización, ya que generan e identifican nuevas oportunidades.

Al medir los recursos necesarios para abordar nuevas oportunidades, los gerentes deben examinar las posibilidades internas y externas, más que asumir que la compañía puede hacer las cosas por sí misma. Para esto, muchas compañías se enfrentan a la conveniencia de crear vastas redes de socios y el reto real es administrar esas redes de manera efectiva. De este modo, una empresa que nutre el capital relacional, cuenta con la habilidad de identificar e interactuar positivamente con los diferentes actores clave alrededor de su negocio, estimulando el potencial de creación de riqueza que trae la ejecución de iniciativas conjuntas mediante la integración de objetivos, recursos, capacidades, planes de acción, mecanismos de control y demás requisitos para el logro de intereses comunes.

\subsubsection{Capital estructural ${ }^{6}$}

Definido como el elemento que permite la creación de riqueza mediante la transformación del trabajo del capital humano. El capital estructural representa el conocimiento que la organización consigue hacer explícito, que ha sistematizado y que ha interiorizado; dicho conocimiento, en un principio, puede estar latente en las personas y en los equipos de la empresa. Quedan incluidos bajo este concepto todos aquellos conocimientos estructurados de los que depende la eficacia y eficiencia interna: la estructura de la organización, los procesos y procedimientos (tales como los desarrollados para la definición de los productos y servicios), los procesos de reflexión estratégica, las tecnologías de la información, la tecnología disponible, propia de la actividad productiva, la propiedad intelectual, etc. En síntesis, el capital estructural representa todos aquellos mecanismos y estructuras de la organización que pueden ayudar a los empleados a optimizar su rendimiento intelectual y, por tanto, el rendimiento empresarial. Para su análisis, se ha clasificado en capital organizativo y capital tecnológico, considerando que estos

\footnotetext{
${ }^{5}$ Por lo general, varios autores coinciden en describir los componentes del capital intelectual desde una perspectiva estática o de variables «stock». En el caso del capital humano, el «stock» de conocimiento está disponible individualmente; es decir, pertenece exclusivamente a cada una de las personas de la organización, quienes de forma voluntaria lo utilizan en su trabajo diario. ORDOÑEZ DE PABLOS, Patricia. «Las cuentas de capital intelectual como complemento del informe anual» En Revista Economía Industrial No. 357 [en línea] http://www.mityc/ MITycCMS/Templates/ListadoPublicacionesPorMateria.aspx Noviembre 19 de 2006. Citado por Arce Sigifredo y Cifuentes Jorge. «Gestión del Conocimiento: reseña sobre tendencias recientes a nivel mundial» Universidad EAN. Grupo de Investigación en Management. Noviembre de 2006.
}

6 [BENAVIDES VElasco, Carlos A.; QUINTANA GARCÍA, Cristina. 2003]. 
dos capitales y sus respectivos componentes interactúan estrechamente y generan escenarios adecuados para que los empleados se motiven y desarrollen su capacidad de aprender y crear iniciativas productivas para las organizaciones.

En la Figura 1 se ilustran los componentes del capital intelectual descritos anteriormente, así como sus relaciones e impacto en el proceso «K»: de asimilación, adaptación y producción de conocimiento.

\subsection{El conocimiento potencial}

Las personas, la organización, el entorno, la tecnología son todas fuentes de datos, información y conocimiento. El modelo lo representa, a través del capital humano, el capital relacional, así como el capital estructural; estos factores y sus relaciones conforman lo que hemos denominado el conocimiento potencial que tiene una organización y que se ilustra como insumo para el proceso $\mathrm{K}$, conocimiento que, a su vez, es enriquecido como resultado de dicho proceso.

Antes de profundizar sobre lo que significa este conocimiento potencial, vale la pena reiterar la naturaleza misma del conocimiento. Si bien las tecnologías permiten la captura, almacenamiento y procesamiento de datos e información, obtener hechos que retornan a nuestras mentes para usos prácticos y creativos es una tarea que involucra mucho más que tecnología. El conocimiento se origina en las personas, se forma en cualquier momento, es producto de la comprensión, de la reflexión, de la memoria, de la intuición, se da cuando surge una necesidad, una situación? De este modo, se reconoce que gran parte del conocimiento útil a las organizaciones reside en la cabeza de las personas, no está escrito ni formalizado y es considerado conocimiento tácito. Entre los diferentes autores que han analizado la naturaleza y las formas del conocimiento, existe consenso al reconocer que en el caso de los conocimientos tácitos, la única posibilidad para capturarlos y almacenarlos es hacer uso de una estructura de conocimiento informal, con el apoyo de actividades como charlas abiertas, entrevistas, reuniones periódicas, consolidación de equipos de trabajo y mecanismos similares.

Dada esta realidad, es el capital humano quien habilita la consolidación de los capitales restantes del modelo; es el concepto más importante por ser fuente de innovación y renovación estratégica de la empresa. Son las personas quienes gracias a su actitudes, aptitudes, conocimientos, experiencias identifican los mejores mecanismos para lograr un buen desempeño y ser fuente de riqueza y oportunidades para las organizaciones.

Sin embargo, la definición de conocimiento no está limitada a la habilidad de la mente humana de concebir o percibir las formas de conocimiento en las cuales éste ha nacido; su creación involucra una alianza entre el conocimiento humano y la inteligencia basada en tecnología, facilitando la consolidación y existencia de una base de conocimiento que esté disponible y con un enorme potencial de ser utilizado y transformado en propuestas que agreguen valor a las organizaciones.

\footnotetext{
7 Es pertinente hacer una clara distinción entre conocimiento, información y datos. Información se puede considerar como un mensaje: típicamente tiene un emisor y un receptor. La información es aquello que lleva a la comprensión. Cada uno de nosotros necesita una medida personal con la cual definir la información. Lo que constituye información para una persona, puede ser simplemente datos para otra. Como señala (Wurman, Richard, 2001) Dato es una clase de información que está estructurada, pero que no ha sido interpretada. Conocimiento puede describirse como información que tiene una intención, uso o propósito. (Tomado de Wurman, Richard . "Angustia informativa». Prentice Hall. Pearson Educación.)
} 
Materializar este conocimiento potencialreconociendo que no todo el que se origina en las personas se puede atrapar implica dar estructura al conocimiento de las organizaciones, lo que exige transformar el conocimiento relevante de intangible a tangible, de tácito a explícito, de informal a formal, configurando repositorios de conocimiento y promoviendo su uso y enriquecimiento. Incluso, una vez lograda la estructura ${ }^{8}$ del conocimiento que se ha desincorporado y lograda su disponibi-lidad para acceso y uso a través de repositorios, es necesario refrescarlo, actualizarlo, mantenerlo.

«La gestión de conocimiento representa un proceso dinámico, que no se limita a la gestión del repositorio de conocimiento existente, sino que promueve la generación de otros nuevos conocimientos, capaces de atender las necesidades y oportunidades emergentes ${ }^{9}$. Así, el conocimiento es un insumo y un producto de las personas y de los grupos de personas que actúan como redes generadoras de conocimiento para la organización, gracias a la interacción con los diferentes grupos de interés internos y externos, así como con otros actores del entorno. La estructura de la organización deberá favorecer y motivar estos escenarios.

Aunque la naturaleza misma de la gestión de Conocimiento está dirigida más a las personas que a las tecnologías, las tecnologías, sin ser un requisito, ofrecen múltiples herramientas de soporte que facilitan esta forma de gestión. Los sistemas de información basados en conocimiento, además de facilitar la captura, el almacenamiento, procesamiento de datos e información, así como la generación de diferentes tipos de reportes, permiten simular procesos de razonamiento para la solución de problemas y, de este modo, dar argumentos que apoyan la toma de decisiones y aumentar la capacidad de respuesta de las empresas.

Para extraer las bondades que ofrecen las tecnologías frente al conocimiento que ya se ha logrado hacer explícito, una iniciativa de gestión de conocimiento debe disponer de un sistema que permita soportar las múltiples misiones críticas alrededor del conocimiento, tales como «....creación, construcción, identificación, captura, adquisición, selección, valoración, organización, enlace, estructuración, formalización, visualización, distribución, retención, mantenimiento, afinación, evolución, acceso, búsqueda y aplicación de conocimiento». ${ }^{10}$

Un sistema de soporte a la gestión de conocimiento tiene como motor las necesidades de los usuarios. Disponer de procesos y tecnologías para identificar y capturar el conocimiento útil para la satisfacción de sus necesidades, contar con repositorios de conocimiento, con procesos para almacenar, buscar, recuperar y hacer el despliegue del mismo son requisitos vitales del sistema.

\footnotetext{
3 El nivel de estructura en el conocimiento se refiere al grado de formalidad y precisión del mismo; afecta directamente la cantidad de procesamiento automatizado que se puede ejecutar debido a que entre más estructurado sea el conocimiento, se emplea semántica más potente y se facilita más al usuario su recuperación y entendimiento. Por ejemplo, las siguientes formas de conocimiento van evolucionando en su grado de estructura, de menor a mayor: conocimiento que reside en la cabeza de las personas (implícito); información almacenada en audio o en videos; documentos de texto planos,; documentos de texto en formato HTML; información textual estructurada (como XML); información estructurada en bases de datos; información categorizada; representación de información basada en lógica. De este modo, el término conocimiento formal se utiliza en el sentido matemático. Frases lógicas como teoremas y ecuaciones se utilizan en una forma muy rigurosa para asegurarse que todas las semánticas son explícitas y las reglas -definidas por los seres humanos- se cumplan. Esto facilita a las máquinas la interpretación de la información y apoyar la creación de conocimiento. Tomado de [HOUSEL, Thomas; BELL, Arthur H. 2001]

9 BENAVIDES VElasCO, Carlos A.; QUINTANA GARCÍA, Cristina. 2003.

10 Maier, R. 2002.
} 
Los repositorios de conocimiento son un elemento clave en los sistemas de apoyo a la gestión de conocimiento y en la tarea de poner a disposición de los diferentes actores de una organización el conocimiento potencial que ésta posee para lograr propósitos creativos. Se reconocen tres tipos de repositorios de conocimiento: documentos en papel, documentos y bases de datos basados en computador, así como las memorias propias ${ }^{11}$.

Los documentos basados en papel usualmente están a disposición para la organización y sus diferentes grupos y residen en repositorios centrales tales como bibliotecas o centros de documentación. Reportes, procedimientos, fotografías, videos, grabaciones de audio y estándares técnicos son algunos ejemplos de este tipo de repositorios, en donde la secuencia cronológica pasa a ser un factor clave ya que refleja, de algún modo, la evolución de la cultura de las organizaciones y los procesos de toma de decisiones. Sin embargo, considerar los documentos basados en papel como una fuente plenamente confiable para la conformación del potencial de conocimiento de una organización es un enfoque riesgoso ya que usualmente no se dispone de un historial estructurado sobre los cambios en dichos documentos, se mantienen varias versiones y se vuelve imprecisa la recuperación de la memoria institucional.

Las bases de datos y los documentos en computador incluyen toda aquella información que se utiliza y administra en los diferentes grupos de la organización. Dicha información puede estar disponible ya sea en equipos de cómputo individuales o residir en bases de datos centralizadas. La demanda de capacidades de almacenamiento de información es múltiple gracias a la digitalización que permite grabaciones no solo de texto sino de audio, imágenes y video. Esta a su vez se convierte en exigentes requisitos tecnológicos ya que demanda arquitecturas robustas en capacidad de almacenamiento y transmisión. Un escenario desarrollado desde este punto de vista, se refiere a compañías que ya han identificado y agregado documentos, textos, imágenes o gráficas y desarrollado aplicaciones empresariales que ponen a disposición estos datos e información, utilizando, incluso, herramientas como el portal para visualizar agendas, diagramas de diseño, información de productos y servicios de la compañía; todo esto con el fin de profundizar en la comprensión de las transacciones del negocio. Sin embrago, este componente del conocimiento potencial, si bien es muy importante, es insuficiente en sí mismo ya que el éxito de un repositorio que hace parte del potencial de conocimiento de una organización, está representado en lograr el uso intensivo de su contenido, la búsqueda y navegación de contenidos, con el fin de hacer que estos sean más dirigidos y a la medida de los procesos internos como de los procesos con otros actores del negocio, apoyando la oportunidad de mejora de los mismos y de creación de nuevos conocimientos.

Las memorias propias están formadas por todos los documentos en papel y basados en computador, así como las memorias y experiencias de cada persona, los cuales son administrados y mantenidos de manera individual. Típicamente, estos documentos se reflejan en libretas de apuntes, agendas, medios físicos aislados, fotocopias, información escrita y no escrita y otros tipos de archivos. Como en los casos anteriores, este componente del potencial de conocimiento también tiene asociados sus

11 Tomado de Murray E. Jennex, San Diego State University . «Knowledge Management Systems». www.management.com.ua 
retos. Usualmente estos documentos carecen de procedimientos y formatos, su existencia y vigencia depende de los criterios de cada persona y refleja la experiencia específica de alguien en particular con la organización, por lo que no necesariamente se encuentra en el estado más adecuado para su interpretación y uso, ni para constituir una base que motive la creación de conocimiento en terceros. Las organizaciones que tienen alta movilidad en sus trabajadores corren el riesgo de perder la memoria institucional y requieren capturar, almacenar y compartir el conocimiento en formas concretas; se trata de hacer explícito un conocimiento que usualmente no está estructurado y es abstracto.

De este modo, las organizaciones que tienen un elevado nivel de automatización y uso de sistemas de información y aplicaciones computarizados, tendrán para el uso de su conocimiento potencial una mayor dependencia de los repositorios basados en computador; otras organizaciones pueden tener mayor dependencia de repositorios físicos o de memorias individuales.

Algunos autores ${ }^{12}$ analizan la problemática ante la cual se enfrentan los nuevos trabajadores que ingresan a una organización, quienes presentan resistencia en utilizar la parte del potencial de conocimiento que está representada en repositorios basados en papel o en computador y prefieren acudir a memorias propias de determinados miembros que tienen mayor antigüedad. Dicho proceso surge mientras los nuevos empleados ganan confianza en la información y el conocimiento, almacenados de manera tangible por y para la organización.

Esta situación destaca el rol importante que tiene la cultura organizacional en la conformación, uso y enriquecimiento del potencial de conocimiento, ya que debe dar un contexto para la creación, estructuración, asimilación, adaptación, difusión, así como las demás misiones críticas, relacionadas con el conocimiento. De esta manera, la cultura organizacional utiliza los tres tipos de repositorios mencionados y, a través de procedimientos adoptados, como hábitos, normas, anécdotas individuales y grupales, , se transmite a nuevos miembros el contexto para el uso de conocimiento, motivando su enriquecimiento y participación en ideas y proyectos innovadores.

\subsection{El proceso $\mathrm{K}$ : de gestión del conocimiento y del capital intelectual}

Varios puntos de partida deben considerarse al analizar el conocimiento y su gestión o administración: dos aspectos que si bien son ambiciosos de manera individual, integrados en una sola disciplina denominada gestión de conocimiento, pasan a ser un reto aún mayor para las organizaciones. Se reconoce que el conocimiento es un producto del cerebro humano, es tácito por naturaleza, pero es conveniente hacerlo explícito. También se ha analizado en este espacio la conveniencia de utilizar tecnologías como sistemas de información y el rol de los repositorios en los mismos, como vehículos que facilitan la captura y el flujo de conocimiento en las organizaciones. La Figura No. 1 destaca cómo el capital estructural y sus diferentes componentes (capital organizacional y capital tecnológico) interactúan y están al servicio del capital humano, potenciando la generación de escenarios adecuados para que los empleados se motiven y desarrollen su capacidad de interpretar y utilizar los datos $y$ la información captada de las relaciones

12 Jennex, M.E. and Olfman, 1. 2004. 
establecidas con el entorno y con la propia organización. Entre los recursos organizacionales que pueden ser utilizados para motivar a los individuos están, la cultura, la estructura, el estilo de dirección, el aprendizaje individual y grupal, los procesos, las tecnologías, entre otros. De todas estas relaciones se espera lograr la conversión de conocimiento tácito en explícito y una vez estructurado, los repositorios de conocimiento facilitan su acceso y uso, para ser asimilados y adaptados, con el objetivo de promover mentes informadas, despertar el sentido de análisis más amplio, más argumentado y, por lo tanto, la habilidad de creación de nuevo conocimiento, conocimiento enriquecido y traducido en innovaciones de productos, de servicios, y/o de procesos en los diferentes niveles de la organización.

En el ámbito internacional existen varios enfoques y modelos relacionados con el conocimiento y su gestión que incluyen el término capital intelectual (denominado también capitales intangibles ${ }^{13}$ ), abarcando aspectos como las competencias y capacidades de los empleados y de la organización, la capacidad de innovación de las personas y equipos de trabajos, la existencia de patentes, el uso de tecnologías de información y comunicación (TIC) como soporte a la estrategia, la imagen corporativa, así como la intensidad de las relaciones con clientes, proveedores y colaboradores.

Figura 2. El proceso $\mathrm{K}$ : Transformación de conocimiento, desarrollo de capacidades de aprendizaje y creatividad, innovación, productividad, competitividad

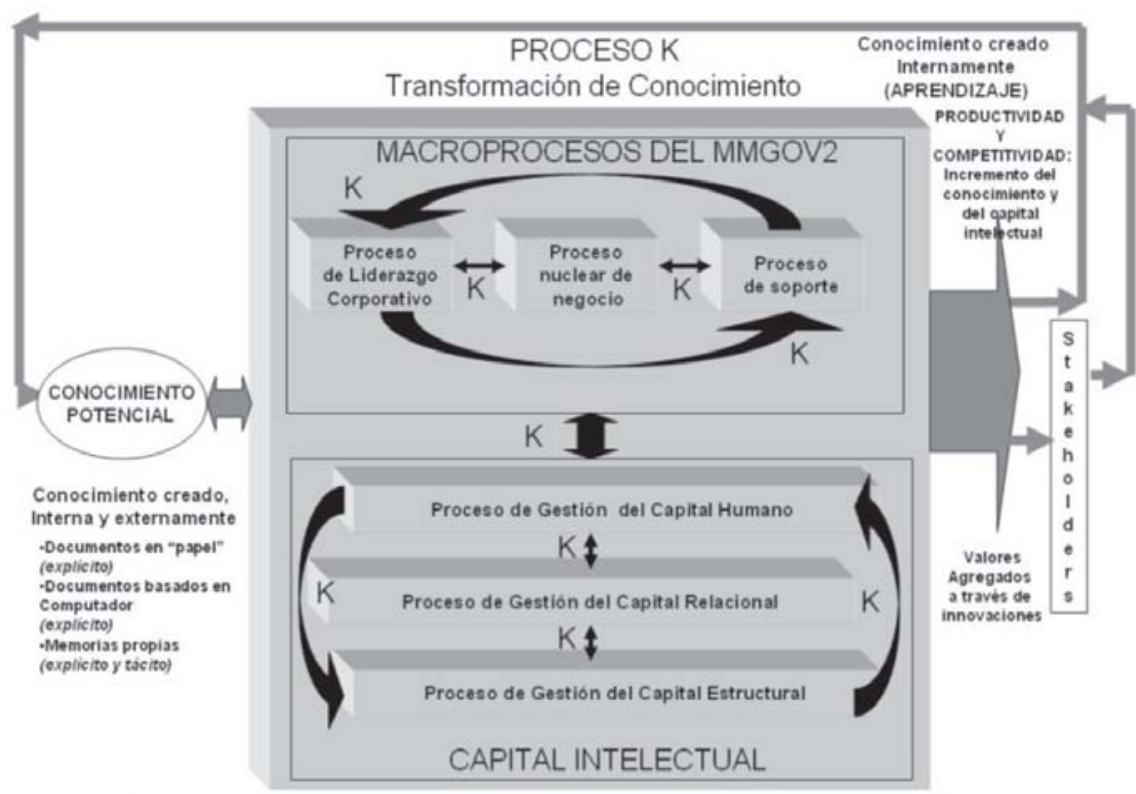

TRANSFORMACION DE CONOCIMIENTO, DESARROLLO DE CAPACIDADES DE APRENDIZAJE Y CREATIVIDAD, INNOVACION, PRODUCTIVIDAD, COMPETITIVIDAD

13 A manera de ejemplo, se retoman algunas definiciones de destacados autores en la materia: «El Capital Intelectual es todo aquello que no se puede tocar pero que puede hacer ganar dinero a la empresa» : Stewart Thomas A. La Nueva Riqueza de las Organizaciones: el capital intelectual. (1991). «Capital Intelectual es el conjunto de activos de una empresa que, pese a no estar reflejados en los estados financieros tradicionales, generan o generarán valor en el futuro para la misma»: Euroforum (1998). Citado por Arce Sigifredo y Cifuentes Jorge, 2006. 
En el modelo propuesto por la Universidad EAN, el Proceso K o proceso de Gestión del Conocimiento y del Capital Intelectual propiamente dicho (Ver Figura 2), se define como el proceso mediante el cual se facilita la administración de los flujos de conocimiento y su transformación proveniente de diferentes fuentes, internas y externas a la organización, que configuran el potencial de conocimiento de la misma:

- El repositorio o inventario inicial de conocimiento.

- El capital intelectual.

- Los diferentes macro procesos propuestos en el modelo para la operación y articulación integral del negocio: proceso de liderazgo corporativo, proceso nuclear de negocio, procesos de soporte. En dichos procesos, el conocimiento actúa como elemento articulador que facilita la gestión integral y coordinada del negocio.

El procesamiento y transformación de dicho conocimiento produce las innovaciones que, gracias a los valores agregados que representan para los diferentes «stakeholders», satisfacen y superan sus expectativas.

Este ciclo a su vez enriquece las capacidades de la organización, haciéndola más productiva y competitiva, dado que incrementa su capital intelectual y contribuye al desarrollo de capacidades de aprendizaje y creatividad en la organización debido al conocimiento internalizado que motiva la creación de nuevo conocimiento. Esta dinámica caracteriza el ciclo virtuoso que promueve el modelo.

\section{PROCESO K}

\section{Knowledge = Conocimiento}

FábriK de Conocimiento

Kmbio=Innovación

Consolidación del $\mathbf{K}_{\text {pital Intelectual }}$

Kmino para la Productividad y Competitividad

Incremento de $\mathbf{K}$ pacidades organizacionales...

Resulta oportuno reflexionar sobre las relaciones entre la gestión del conocimiento y la gestión del capital intelectual. Una de las interpretaciones con las que el modelo encuentra gran identidad establece que «... los resultados de una gestión eficaz de conocimiento, configurarán el capital intelectual de una empresa.... ${ }^{14}$. La gestión del capital intelectual se preocupa por establecer indicadores que tratan de valorar y medir los activos intangibles de una organización; se concentra en crear, identificar y gestionar eficazmente todos aquellos activos intelectuales que se requieren para el logro de los objetivos de la empresa y la ejecución exitosa de sus estrategias. La gestión del conocimiento, por el contrario, se preocupa por ofrecer políticas que faciliten la creación,

14 Edvinsson, 1997. «Developing Intellectual Capital at Skandia». El Modelo Navigator de Skandia, es uno de los modelos reconocidos internacionalmente para la medición del capital intelectual. La principal línea de argumentación de Leif Edvisson es la diferencia entre los valores de la empresa en libros y los de mercado. Esta diferencia se debe a un conjunto de activos intangibles, que no quedan reflejados en la contabilidad tradicional, pero que el mercado reconoce como futuros flujos de caja. Para poder gestionar estos valores, es necesario hacerlos visibles. 
difusión e institucionalización del conocimiento en la organización ${ }^{15}$; representa un proceso dinámico, que no se limita a la gestión del repositorio de conocimiento existente, sino que promueve la generación de otros nuevos conocimientos, capaces de atender las nuevas necesidades y oportunidades. Esta doble dimensión de la gestión del conocimiento (gestionar el conocimiento desincorporado y representado en repositorios, así como motivar y liberar el conocimiento potencial) ha dado paso al tratamiento de dos disciplinas: administrar el conocimiento actualmente disponible («Knowledge Management» propiamente dicho) y promover la capacidad de aprender mediante la generación de nuevos conocimientos («Learning Organization») ${ }^{16}$.

Las anteriores definiciones destacan la estrecha relación, bidireccional y de causa/ efecto, entre ambas disciplinas: gestionar conocimiento implica consolidar e incrementar el capital intelectual y, a su vez, el capital intelectual es fuente de conocimiento que demanda mejores prácticas de gestión para desarrollar la habilidad de traducir en tangible los intangibles que tienen la capacidad de impactar positivamente los resultados de las organizaciones. De esta manera, los bienes de conocimiento en sus variadas formas (los requeridos y producidos a lo largo de los diferentes procesos -de liderazgo corporativo, de negocio y de soporte-, así como los requeridos y producidos en los procesos de consolidación del capital intelectual (capital, humano, capital estructural y capital relacional)), fluyendo a través de redes (humanas y físicas) son los activos que dirigen el crecimiento y la creación de valor, como lo destaca la Figura 2.

\subsubsection{Fuentes de conocimiento del proceso $\mathrm{K}$}

Estos conceptos son interpretados y adoptados en el modelo propuesto. El proceso $\mathrm{K}$, utiliza las diferentes fuentes de conocimiento para las organizaciones: las personas (sus conocimientos, valores, capacidades, experiencias); la organización (su conocimiento, su experiencia existente en las rutinas, sistemas, procesos, cultura, estilo de dirección); la tecnología, así como las relaciones con el entorno o mercado.

Dichas fuentes de conocimiento configuran el conocimiento potencial y son utilizadas para satisfacer los intereses de los «stakeholders» a través de valores agregados $\mathrm{y}$, a su vez, incrementar las capacidades y competencias de la organización. De este modo, revisando nuevamente la Figura 1 para apoyar la comprensión de las relaciones sugeridas se identifica:

- El proceso $\mathrm{K}$ transforma conocimiento proveniente del capital intelectual, representado en las relaciones de la empresa con sus «stakeholders» y otros actores del entorno (capital relacional), el cual es capturado por los recursos humanos (capital humano) de la organización, alentados por una estructura que motive su capacidad de aprender y crear (capital estructural). Para el cumplimiento de este objetivo, es imprescindible generar un clima positivo para el desarrollo de nuevos conocimientos, así como la difusión y administración de los conocimientos existentes, lo que exige una filosofía de trabajo con un nivel de identidad laboral que

15 LLORIA ARAMBURO Ma Begoña. 2006]. Citado por Arce Sigifredo y Cifuentes Jorge, 2006.
16 UDAONDO, M. 2000]. Citado por BENAVIDES VELASCO, Carlos A. y QUINTANA GARCÍA, Cristina, 2003. 
despierte la creatividad individual y grupal, con actitudes positivas y proactivas, en un ambiente de motivación permanente que reconozca a los empleados como la más valiosa fuente de conocimiento para desarrollar innovaciones.

- El proceso K transforma conocimiento creado internamente en la ejecución misma de los macro procesos del MMGOV2 sugeridos para representar esquemáticamente una organización: el macro proceso de liderazgo corporativo, el macro proceso nuclear de negocios y el macro proceso de soporte. En este sentido, se reconoce que el proceso $\mathrm{K}$ coexiste con los macroprocesos mencionados, cuyas entradas y salidas mantienen un flujo de conocimiento con el mismo, en una relación de dualidad y simultaneidad entre procesos ${ }^{17}$. Así, en su ejecución, el proceso $\mathrm{K}$ activa los macro procesos y a su vez, en la ejecución de los macro procesos se activa el proceso $\mathrm{K}$.

- El proceso K transforma el conocimiento que reside en el repositorio de conocimiento proveniente de las dos fuentes de conocimiento anteriormente mencionadas, el cual es desincorporado y estructurado para el servicio de la organización gracias a la existencia de sistemas de apoyo a la gestión de conocimiento, conformados, no solo por el repositorio, sino por tecnologías y procesos para almacenar, buscar, recuperar y hacer el despliegue de conocimiento.

De este modo, el proceso $\mathrm{K}$ habilita muchos otros procesos y se nutre de los mismos, en un intercambio de entradas y salidas que asegura el desarrollo y aplicación de todo tipo de conocimiento que constituye oportunidad de mejora y crecimiento para la organización: tanto el conocimiento proveniente de fuentes externas, como el conocimiento creado y recreado internamente.

\subsubsection{Resultados del proceso $\mathrm{K}$}

Varios objetivos se pueden perseguir a través de una iniciativa de gestión de conocimiento, tales como: abrir nuevas posibilidades (es decir, innovar); obtener información en el tiempo y momentos adecuados para aumentar la capacidad de respuesta de las organizaciones; aumentar y mejorar la productividad y competitividad, entre otros. El modelo propuesto promueve el logro de estos resultados ya que considera:

- El fortalecimiento de las capacidades de aprendizaje de la compañía, como un resultado de la gestión de conocimiento aplicada a sus capitales intangibles: un capital humano sólido y creativo, unas relaciones productivas tanto internas como con el entorno, una estructura organizacional que ofrece escenarios adecuados para la operación con alto nivel de productividad y competitividad, así como la visualización y atención de oportunidades de mayor desarrollo.

- La innovación en procesos, como un resultado de la gestión de conocimiento, aplicada al macro proceso de liderazgo corporativo

- La innovación en productos y/o servicios, así como en el proceso mismo, como un resultado de la gestión de conocimiento, aplicada al macro proceso nuclear de negocio.

17 Estos conceptos de coexistencia, dualidad, recurrencia y autorreferencia entre procesos, que aplican plenamente entre los procesos del MMGOV2, son interpretados del artículo «Diseño de Organizaciones para la Creación de Conocimiento», escrito por Andrés Velásquez. Entregado en mayo de 2006, Aprobado en julio de 2006 y publicado en la Revista EAN No. 58, Septiembre a Diciembre de 2006. 
- La innovación en procesos, como un resultado de la Gestión de Conocimiento aplicada al macro proceso de Soporte.

- La eficiencia y eficacia en las operaciones de la compañía requeridas para llevar a cabo cada uno de los macroprocesos citados, representadas en el flujo constante de conocimiento entre estos y el proceso $\mathrm{K}$. Los macro proceso de liderazgo corporativo, nuclear de negocio, de soporte, gracias a este flujo de conocimiento, obtienen y suministran los datos, la información y el conocimiento requerido para fortalecer la capacidad de respuesta de las organizaciones y agilizar la toma de decisiones.

A continuación se especifican algunos de los resultados deseables al incorporar prácticas de gestión al conocimiento, reconocido como insumo y/o producto indispensable para la permanente mejora de los diferentes procesos.

\section{Resultados de la gestión de Conocimiento aplicada a los procesos que configuran el capital intelectual de las organizaciones}

\section{- En el proceso de gestión del capital humano}

En este proceso se incluyen diferentes actores: personal de la empresa, los clientes, los proveedores y los diferentes tipos de aliados de las organizaciones. Mediante la aplicación de mejores prácticas -en temas como gestión por competencias, desarrollo de incentivos, desarrollo del compromiso, de la participación, formación de la creatividad y de equipos de alto rendimiento, entre otros- un programa de gestión de conocimiento aplicado al capital humano deberá producir resultados, tales como ,personal calificado, con competencias, motivado, comprometido, creativo, con incentivos, participativo y equipos de trabajo de alto desempeño.

\section{- En el proceso de gestión del capital relacional}

El capital relacional se establece entre actores internos, externos, alianzas, asociaciones, cadenas productivas. Todos estos actores motivados por procesos, tales como, comunicación, gestión de alianzas, procesos de negociación, de planeación y alineación, gestión de proyectos e inteligencia competitiva, entre otros, tienen un impacto positivo en las organizaciones, gracias a la consolidación de redes de negocios; proyectos conjuntos; comunicación efectiva interna y externa; sinergias; liderazgo; manejo de grupos; manejo de proyectos; alineación entre objetivos, procesos y capacidades; capacidades de interfase; capacidades en mercadeo; encadenamientos $^{18}$. Dichos resultados serán, a su vez, indicadores de un programa efectivo de gestión de conocimiento aplicado al capital relacional de las organizaciones.

\section{- En el proceso de gestión del capital estructural}

Como se ha indicado, el capital estructural es en definitiva el conocimiento inmerso en las rutinas de una organización; es el elemento

\footnotetext{
18 Aquí, el concepto de «Clusters» y cadenas empresariales conforman una estrategia importante, pero el reto va más allá: cómo lograr, gracias a la consolidación de un capital relacional a la medida y conveniencia de cada organización, vincular dichos «clusters» a cadenas de producción internacionales, a la consolidación de alianzas con entidades extranjeras y pertenecer a dinámicas propicias para la asimilación, adaptación y generación de conocimiento que se traduzca en nuevas y mejores oportunidades para la organización.
} 
que permite crear riqueza mediante la transformación del trabajo del capital humano; representa el conocimiento que la empresa logra hacer explícito, sistematizado e internalizado. Este tipo de capital puede encontrarse latente tanto en las personas como en los equipos de la empresa y representa todos aquellos mecanismos y estructuras de la organización que pueden ayudar a los empleados a optimizar su rendimiento intelectual y, por lo tanto, el rendimiento de la organización. En términos prácticos, se ha sugerido su análisis clasificándolo con dos componentes: capital tecnológico y capital organizacional.

De este modo, por ejemplo, si nos referimos al componente tecnológico del capital estructural, mencionaríamos que un programa de gestión de conocimiento dirigido a fortalecer el capital tecnológico requerirá como insumos una serie de tecnologías periféricas y nucleares a las cuales se aplican prácticas de gestión como inteligencia tecnológica, análisis de brechas tecnológicas, gestión de adquisición de tecnología, vigilancia tecnológica, prospectiva tecnológica, análisis de impacto, procesos de asimilación y transferencia de tecnología, entre otros. Como resultado, se optimizaría la utilización de infraestructura tecnológica de soporte a las diferentes operaciones del negocio, extrayendo el mayor beneficio a sus potencialidades: ser motores de productividad y competitividad para las organizaciones; permitir consolidar ventajas competitivas sostenibles ${ }^{19}$, difíciles de imitar, superiores a la competencia y aplicables a múltiples situaciones.
Si nos referimos al enfoque por procesos como una de las estrategias que favorecen la solidez del capital organizacional (Ver figura 1), la gestión de conocimiento producirá resultados, tales como, la innovación y optimización de los procesos, aspectos que responden a la necesaria fusión y coordinación de actividades de seres humanos y de las facilidades que ofrecen los diferentes sistemas y tecnologías de información. La gestión por procesos apoyada en el rescate del conocimiento como su elemento creador de valor, permitirá administrar el ciclo de vida de cada proceso, empezando por la definición precisa de su aporte a los objetivos del negocio, pasando por su desarrollo, ejecución, medida, cambio y reasignación de recursos para su mejoramiento continuo y permitiendo a las organizaciones trascender más allá del uso de tácticas reactivas para mantener su operación e involucrarse en una gestión estratégica, analítica y proactiva.

\section{Resultados de la gestión de conocimiento aplicada a los macroprocesos generales que propone el modelo para representar una organización: de liderazgo corporativo, nuclear de negocio, de soporte}

Difícilmente se puede definir con límites cuál es ese saber que requieren las empresas para su exitosa operación; más difícil se convierte el propósito, si lo que se pretende es hacer

\footnotetext{
${ }^{19}$ Ocasionalmente el Sistema de Información en sí mismo es la pieza clave en la iniciativa de gestión del conocimiento que permite a las compañías consolidar la ventaja competitiva. Un ejemplo es Wal-Mart, quien utiliza una extranet para integrar toda su cadena de suministro. Otro ejemplo es Dell Computer, que utiliza Internet para mercadear PCs ensamblados a la medida de las especificaciones de los usuarios, beneficiándose de los bajos costos de promoción y distribución. Vale la pena citar también casos como e-Bay, Amazon.com, Federal Express, entre otros.
} 
útil este ejercicio para cualquier empresa, de cualquier sector productivo, pues no se puede desconocer que cada negocio tiene sus necesidades de conocimiento específico y a la medida. No obstante, en busca de una base común que permita afinar las estrategias frente al conocimiento que cada empresa debe nutrir, en este espacio se presenta, a manera de ejemplo, lo que puede considerarse como mínima información, datos y conocimientos que ayudan a las empresas a realizar sus negocios.

Para este fin, resulta de utilidad dar una vista a algunos procesos básicos que desarrollan las diferentes empresas en su actividad: la planeación estratégica, la toma de decisiones, el monitoreo al desempeño (como parte de los procesos de liderazgo corporativo); la operación propiamente dicha para la producción de bienes y/o servicios (lo que constituye el proceso nuclear de negocio), la gestión logística, financiera y de mercados (lo que hace parte del proceso de soporte). Este ejercicio revela necesidades de identificar, mantener, procesar e interpretar datos e información, tales como:

Para soportar las operaciones del negocio:

- Datos de ventas, compras, inversiones, nómina y oros registros requeridos para la contabilidad.

- Procesamiento de esos registros contables en reportes de ingresos, gastos, balances y otras modalidades de información financiera.

- Datos de inventario, datos de procesos, datos de reparación y mantenimiento de equipos, datos de la cadena de suministro y otros registros de operaciones y producción.

- Programaciones de producción, controles de producción, sistemas de inventario y sistemas de monitoreo a la producción.
- Datos de personal, datos de salarios, historia de empleados y otros registros relacionados con recursos humanos.

- Reportes de gastos en el capital humano y reportes basados en su desempeño.

- Datos del mercado, perfiles de clientes, historiales de compras de los clientes, datos de investigación del mercado, datos de publicidad y otros registros de la actividad de mercado.

- Reportes de elasticidad con respecto a la publicidad, planes de mercadeo y reportes de la actividad en ventas.

- Datos de inteligencia de negocios, datos de análisis de la competencia, datos de la industria, objetivos corporativos y otros registros de gestión estratégica.

- Reportes de tendencias de la industria, participaciones en el mercado, objetivos misionales y modelos de portafolios.

Los datos e información convertidos en conocimiento para la toma de decisiones, deben permitir a los empresarios formularse y resolver preguntas en diferentes escenarios, tales como: ¿qué pasa si incrementamos el precio en un determinado porcentaje? ¿Qué pasa si lo disminuimos? ¿Qué pasa si tomamos esas acciones ahora y otras en tres meses? ¿Qué pasa ante situaciones de contingencia tales como el incremento de la inflación en un porcentaje diferente al asumido inicialmente? ¿Qué pasa si enfrentamos una nueva amenaza de competencia? Podrían surgir múltiples preguntas también, si las eventualidades ocurren por cambios en los recursos, capacidades, procesos o condiciones internas de la compañía. 
Si lo que interesa es el monitoreo al desempeño organizacional, los datos e información traducidos en conocimiento, deben asegurar el control del conjunto de funciones de la compañía, la administración en tiempo real de los costos de disfunciones que causan diferencias en las cuentas, la evaluación y el reporte de resultados del ejercicio contable, todo esto articulado con la evaluación y reportes de calidad de los resultados para el cumplimiento y superación de las expectativas de los diferentes grupos de interés para quienes trabaja la compañía. Surge, por lo tanto, la necesidad de analizar, no solo estadísticas y datos, sino el cumplimiento de los objetivos más relevantes de la compañía, conociendo incluso señales de alerta con la frecuencia conveniente para administrar cada nivel de la organización, con respecto a las desviaciones que se den entre los resultados y los objetivos preestablecidos.

La actividad de planeación estratégica podría soportarse en la utilización de todo lo anterior para implementar, controlar y monitorear planes, estrategias, tácticas, nuevos productos, nuevos modelos o esquemas de negocios. Dado que el propósito de la planeación estratégica es encontrar formas de utilizar las fortalezas de la empresa para aprovechar las oportunidades atractivas que ofrezca el entorno, saber del negocio también es un requisito en este ejercicio. El plan estratégico de una empresa define su misión, los objetivos generales, los tipos de negocio en los que participará y los objetivos para cada uno, decidiendo qué se quiere hacer con cada unidad de negocios durante un intervalo de tiempo determinado.

Esto implica analizar para cada unidad qué tan atractivo es el mercado, en qué fase se encuentra la tasa de crecimiento del mercado y medir qué tan fuerte es la empresa en ese mercado. Con el paso del tiempo, cada unidad de negocio de la compañía cambia de valor ya que tiene un ciclo de vida y se hace necesario establecer su estrategia general: invertir más en la unidad comercial para acrecentar su participación, o invertir apenas lo suficiente para mantener su participación en el nivel actual, o cosechar a partir de la unidad, obteniendo el flujo de efectivo a corto plazo más alto posible sin pensar en el efecto a largo plazo, o si es necesario, deshacerse de la unidad, vendiéndola o descontinuándola e invirtiendo los recursos en otra cosa. De este modo, las empresas necesitan añadir continuamente productos y unidades nuevos conformando un portafolio de unidades de negocio donde los respectivos ciclos de vida se compensen y se mantenga una tendencia de crecimiento. Además de evaluar los negocios actuales, el diseño de dicho portafolio de negocios implica identificar las nuevas posibilidades que la empresa debería considerar en el futuro. De allí la importancia de la innovación, aquella actividad que se nutre de conocimiento para aprovechar las oportunidades atractivas que ofrece el entorno, traduciéndolas en productos, servicios o procesos nuevos y/o mejorados que agregan valor a la compañía. 


\section{INNOVACIÓN, RESULTADO DEL PROCESO K Y ESTRATEGIA DE PRODUCTIVIDAD Y COMPETITIVIDAD}

$\mathbf{E}$ organización a través de los macro procesos de liderazgo corporativo, nuclear de negocio y de soporte, así como sus interacciones con el macroproceso K, -de gestión del conocimiento y del capital intelectual-. De cada uno de estos procesos se espera como resultado la innovación, ya sea en el proceso mismo o en los productos y/o servicios del macro proceso. En este sentido, se ha decidido motivar la innovación como estrategia que permita a las organizaciones satisfacer y superar las expectativas y necesidades de sus diferentes grupos de interés, reconociendo que los productos y los procesos tienen en general un ciclo de vida cada vez más corto y se hace necesario el cambio, entendido también como un sinónimo de innovación.

¿Por qué cambiar? No solo la necesidad de lograr mayor eficiencia, eficacia, productividad y competitividad de las organizaciones son los factores que invitan al cambio. Aún estando en una posición de liderazgo en el mercado, no se puede ignorar que nadie tiene la llave del éxito de manera permanente. Varias externalidades que afectan profundamente los negocios obligan también al cambio, tales como el progreso técnico -nuevos productos con mejores características pueden incluso desplazar productos actuales-, la internacionalización de la economía-la competencia se agudiza, no solo entre países vecinos sino que se superan las fronteras geográficas, presentando amenazas y oportunidades, incluso con países remotos-y la desmasificación de los mercados -los productos y servicios se ofrecen cada vez con mayor nivel de personalización y a la medida de necesidades muy específicas- . Todo lo anterior demanda elevada flexibilidad, asumir nuevas formas de hacer las cosas, romper rutinas por muy exitosas y tradicionales que hayan resultado en el pasado, buscar permanentemente nuevas y mejores alternativas y,en síntesis, innovar ${ }^{20}$.

La razón última de las empresas para mejorar es la optimización de sus resultados, ya sea aumentando la demanda o reduciendo los costos, por ejemplo. Un nuevo producto o proceso puede poner al innovador en una posición ventajosa en el mercado. Cuando se trata de innovaciones de proceso que consiguen ganancias de productividad, la empresa se beneficia de una ventaja de costos sobre sus competidores; puede obtener un mejor margen de beneficio sobre el precio, o según la elasticidad de la demanda puede bajar sus precios ganando cuota de mercado sobre su competencia. Cuando se trata de una innovación de producto, la empresa puede obtener una ventaja competitiva lanzando este nuevo producto, lo que le permite aumentar la demanda y su margen de beneficios.

\footnotetext{
${ }^{20}$ El tratamiento al tema de Innovación que se da en el presente documento, está basado principalmente en información tomada, sintetizada y/o re estructurada a partir de conceptos presentados en el Manual de Oslo. Guía para la recogida e interpretación de datos sobre innovación. $3^{\text {a }}$. Edición. OCDE, Organización de Cooperación y Desarrollo Económicos. Oficina de Estadísticas de las Comunidades Europeas. Este manual es la expresión de un consenso sobre la demanda de indicadores sobre la innovación, que se basa en los imperativos estratégicos y la teoría económica, las definiciones y el alcance de la innovación, así como en los resultados obtenidos en encuestas anteriores. El Manual es administrado en común por la OCDE y Eurostat, se ha escrito por y para expertos de más de treinta países que recogen y analizan los datos relativos a la innovación. El Manual tiene por objeto presentar un conjunto sólido de directrices que pueden ser aplicadas para establecer indicadores significativos de la innovación.
} 
Pero la demanda también puede aumentarse mediante la diferenciación de los productos, abriendo nuevos mercados e influyendo sobre la demanda de productos existentes. Por otro lado, los cambios en los métodos organizativos permiten mejorar la calidad y eficiencia del funcionamiento de las organizaciones $y$, por lo tanto, aumentar la demanda o reducir los costos. La innovación puede también mejorar los resultados reforzando la aptitud de la empresa a innovar; por ejemplo, la mejora de las capacidades de los métodos de producción puede permitir poner a punto una nueva gama de productos y la adopción de nuevos métodos organizativos puede mejorar la aptitud de la empresa a apropiarse y a crear un nuevo conocimiento que podría utilizarse para desarrollar otras innovaciones; hablamos de este modo de organizaciones innovadoras, que aprenden a aprender para crear de manera continua.

\subsection{Algunas definiciones de innovación}

Hasta este punto se han mencionado innovaciones de productos, innovaciones de procesos y también se han mencionado otros aspectos que son objeto de cambio para mejora. Definiciones clásicas de innovación ${ }^{21}$ incluyen los siguientes casos:

- La introducción en el mercado de un nuevo bien o de una nueva clase de bienes, es decir, un bien con el cual los consumidores no están aún familiarizados.

- La introducción de un nuevo método de producción, es decir, de un método aún no experimentado en la rama de la industria afectada, que requiere fundamentarse en un nuevo descubrimiento científico; también puede existir innovación en una nueva forma de tratar comercialmente un nuevo producto.

- La apertura de un mercado en un país, ya sea si este mercado ya existía o no en dicho país.

- La conquista de una nueva fuente de suministro de materias primas o de productos semielaborados, nuevamente sin tener en cuenta si esta fuente ya existe o ha de ser creada.

- La implantación de una nueva estructura en un mercado, como por ejemplo, la creación de una posición de monopolio.

Las innovaciones se pueden considerar de carácter predominantemente tecnológico o predominantemente comercial; es decir, con o sin protagonismo de la tecnología, entendida como la aplicación industrial de los descubrimientos científicos. La innovación se considera tecnológica cuando está relacionada con la ciencia y la tecnología. De forma sencilla, se reconoce que la innovación desde la perspectiva tecnológica supone para la empresa la introducción de un cambio técnico en los productos o procesos ${ }^{22}$. De acuerdo con Escorsa, 2003, algunos ejemplos de innovaciones de carácter predominantemente tecnológico incluyen casos como el uso de nuevos materiales, nuevos ingredientes, nuevos procedimientos. Innovaciones de carácter predominantemente comercial incluyen aspectos como la nueva presentación de un producto, nuevas formas de distribución de un producto, nueva aplicación de un producto conocido, un nuevo sistema comercial. Sin embargo, muchas innovaciones resultan de combinaciones diversas.

\footnotetext{
${ }^{21}$ Joseph A. Schumpeter, economista Austriaco, quien fue el primero en destacar la importancia de los fenómenos tecnológicos en el crecimiento económico, definió la innovación en 1934, en un sentido más general que el de las innovaciones tecnológicas, como se indica.

22 Escorsa Pere (2003). Capítulo 1: «La Innovación en Tecnología e Innovación en la empresa. Ediciones UPC.
} 
El Manual de Oslo, $3^{\text {a }}$ Edición, define cuatro tipos de innovaciones que incluyen una amplia gama de cambios en las actividades de una organización: innovaciones de producto, innovaciones de proceso, innovaciones organizativas e innovaciones de mercadotecnia.

Esta clasificación básicamente coincide con las dimensiones de innovación que tratan las definiciones previas: nuevos bienes o servicios, nuevos métodos o procesos, nuevos mercados o esquemas de comercialización, nuevos proveedores. Como lo manifiesta el citado Manual de Oslo, las innovaciones de producto implican cambios significativos de las características de los bienes o servicios, ya sean nuevos o mejoras de los existentes. Las innovaciones de proceso son cambios significativos en los métodos de producción y de distribución. Las innovaciones organizativas se refieren a la puesta en práctica de nuevos métodos de organización. Estos pueden ser cambios en las prácticas de la empresa, en la organización del lugar de trabajo o en las relaciones exteriores de la empresa. Las innovaciones de mercadotecnia implican la puesta en marcha de nuevos métodos de comercialización.

Este último enfoque surge como respuesta a la necesidad cada vez más sentida de reconocer que el concepto de innovación en productos y procesos, usualmente asociado al sector manufacturero, no refleja en una forma adecuada gran parte de la innovación en el sector servicios. De allí, la importancia de destacar la innovación tecnológica: la innovación en mercadotecnia y la innovación organizativa.

Se observa en las diferentes definiciones que la innovación acaba con la introducción con éxito en el mercado: los nuevos productos, procesos o servicios deben ser aceptados por el mercado y, por lo tanto, ser competitivos.
Así, identificar todo el conjunto de cambios que las empresas introducen para aumentar su rendimiento y su éxito, mejorando los resultados económicos, exige un marco más amplio, que el que sirve para medir la innovación tecnológica de producto y de proceso. Al incluir las innovaciones en mercadotecnia y organización, se obtiene un marco más completo, capaz de reflejar los cambios que influyen en los resultados de las empresas y contribuyen a la acumulación del conocimiento.

Las innovaciones organizativas no solamente constituyen un factor de apoyo para las innovaciones de producto y proceso; ellas mismas pueden influir de manera considerable en los resultados de la organización: mejorar la calidad y eficiencia del trabajo, favorecer el intercambio de información, dotar a las empresas con una mayor capacidad de aprendizaje y de utilización de nuevos conocimientos y tecnologías.

Las empresas también pueden destinar recursos considerables a los estudios de mercado y al desarrollo de nuevos métodos de comercialización, tales como la entrada en nuevos mercados o segmentos de mercado y el desarrollo de nuevos métodos de promoción de sus productos. Estos nuevos métodos de comercialización pueden ser determinantes en los resultados de la empresa y/o marcar el éxito de nuevos productos. Los estudios de mercado y los contactos con los clientes pueden ser factores clave en el desarrollo de productos y procesos mediante la innovación motivada por la demanda. De este modo, existe una interdependencia entre los diferentes tipos de innovación, donde los cambios organizativos pueden liberar los beneficios de otros tipos de innovación. 


\subsection{Reflexiones sobre la innovación en empresas colombianas}

El objetivo de fortalecer y aumentar la viabilidad de la industria nacional en sus diferentes sectores, exige la alineación de capacidades, voluntades, políticas y recursos tanto de quienes constituyen y generan el entorno de la oferta, como de su comunidad usuaria y, por lo tanto, principal promotora. De este modo, se requieren acciones correctivas y preventivas para favorecer el ambiente de desarrollo de nuestras industrias. Esta reflexión constituye un acercamiento a los temas cuya modificación está en manos de los empresarios, del gobierno $y$, en general, de los diferentes sectores que no solo producen sino que consumen producción nacional, productos y servicios resultantes de la aplicación que los empresarios colombianos hacen del conocimiento relevante para sus diferentes negocios, así como de la apropiación de mejores prácticas para la gestión de dicho conocimiento.

Existen múltiples necesidades de transferencia, apropiación y creación de conocimiento e implantación de tecnologías de soporte en las empresas de los diferentes sectores industriales: el adecuado nivel de automatización en su operación y administración, así como la cultura de planeación, ejecución y control apoyados en contenidos de información única y confiable, que dinamicen los ciclos de aprendizaje y creación individual y grupal en las organizaciones, son factores diferenciadores que fortalecen la competitividad empresarial y su contribución al desarrollo económico y social del país.

En el país se han llevado a cabo diferentes iniciativas para diagnosticar la problemática y los retos de las empresas ante su necesidad de fortalecerse no solo mejorando el desempeño de sus negocios actuales sino fijando trayectorias innovadoras en diferentes dimensiones, dadas las condiciones cambiantes del entorno y las exigencias cada vez mayores para mantener participación y crecimiento en los diferentes mercados. Varios elementos de la reflexión presentada a continuación, son tomados del análisis realizado a través del proyecto RED-ET ${ }^{23}$ el cual promovió, a través de encuestas y entrevistas directas, la divulgación de opiniones y recomendaciones de expertos y empresarios de diferentes líneas de producción de industriales nacionales en Electrónica, Telecomunicaciones e Informática (ETI), para identificar las debilidades y amenazas de esta industria nacional. Las industrias ETI tienen una naturaleza transversal, ya que por las soluciones que ofrecen, basadas en tecnología, son requeridas por todos los sectores productivos restantes, facilitando su automatización en diferentes niveles y promoviendo la eficiencia, eficacia y agilidad en sus operaciones.

El estudio realizado analizó la situación tanto de las empresas que producen soluciones tecnológicas en ETI, como de sus empresas usuarias. Por considerar que existe una estrecha relación entre los retos y oportunidades de dichas industrias con lo que enfrentan los empresarios de pequeñas y medianas empresas de los diferentes sectores económicos del país, a continuación se citan las principales reflexiones que permiten caracterizar la situación de empresas colombianas ante la necesidad de desarrollar y fortalecer sus capacidades de innovación como estrategia para el aumento de su productividad y competitividad.

\footnotetext{
${ }^{23}$ Proyecto RED-ETI. COLCIENCIAS-CINTEL-ITEC,CIF y CATI.» Retos y oportunidades de la Industria Nacional en ETI frente a sectores estratégicos del desarrollo del país». Octubre de 2002. Iniciativa desarrollada durante el periodo de Septiembre del 2001 hasta Octubre del 2002. Luz Victoria Díaz R, Gerente del Proyecto.
} 
Entre las necesidades insatisfechas y debilidades de las empresas se encontraron aspectos que fácilmente se pueden relacionar con la necesidad de consolidar y fortalecer la gestión del conocimiento y del capital intelectual en las organizaciones y se ilustran a manera de ejemplo:

\section{Con respecto al capital relacional:}

- Insuficiente conocimiento de sus clientes actuales, de los productos y servicios que están demandando.

- Insuficiente conocimiento de los clientes potenciales (locales, nacionales e internacionales), de los productos y servicios que se están demandando.

- Insuficiente conocimiento de la competencia tanto directa como la que está representada en productos y/o servicios potencialmente sustitutos a la oferta actual.

- Insuficiente conocimiento del mercado internacional, no solo en cuanto a competencia, sino a alternativas de proveedores, distribuidores, diferentes actores y organismos sectoriales, regulación, políticas, procedimientos de internacionalización, etc.

- Dificultad para identificar y contratar asesorías provenientes de expertos (organizaciones o personas) nacionales e internacionales.

- Debilidades y dificultades para identificar los socios estratégicos que le permitan mejorar y diversificar su oferta.

\section{Con respecto al capital humano:}

- Baja o nula disponibilidad de recursos humanos al interior de la organización, que tengan habilidad y conocimientos adecuados para interactuar con diferentes disciplinas (ej: operativas, técnicas, administrativas y otras) y lograr el diagnóstico integral de la necesidad del cliente.

- Debilidad en los niveles de especialización que se requiere en los recursos humanos para la participación y/o liderazgo en proyectos multidisciplinarios en general y para la ejecución de proyectos que involucran conocimientos técnicos específicos, en particular.

- Necesidades de capacitación y de desarrollo de competencias específicas para los diferentes perfiles de recursos humanos que requiere cada negocio, en el ámbito conceptual básico y avanzado

\section{Con respecto al capital estructural:}

- Ausencia o debilidad de infraestructura de laboratorios y herramientas para diseño y pruebas de prototipos, ya sea de productos o servicios.

- Necesidad de realizar monitoreo tecnológico e interpretar los retos y oportunidades que las tendencias internacionales representan para el negocio.

- Dificultades para la identificación de fuentes de financiación y acceso a recursos financieros para emprender proyectos de investigación.

\section{Con respecto a los procesos nucleares de negocio:}

- Necesidad de aplicar estándares, metodologías de desarrollo e indicadores de calidad en su producción.

- Necesidad de formalizar y fortalecer el mercadeo y publicidad de sus productos y servicios 


\section{Con respecto a los procesos de soporte:}

- Debilidades y dificultades para dimensionar los recursos reales que demanda el desarrollo de productos y servicios actuales, así como los recursos requeridos para el desarrollo de nuevas iniciativas (como dinero, tiempo, personal).

- Debilidades y dificultades para dimensionar las pérdidas en las que se está incurriendo en el negocio, originadas por insuficiente $o$ inadecuada automatización en la operación, o por debilidades en otros aspectos de gestión organizacional.

\section{Con respecto a los procesos de liderazgo corporativo:}

- Necesidad de identificar y analizar prácticas internacionales y nuevos modelos de negocio, orientados a segmento y no a productos.

- Necesidad de conocer los mejores criterios de segmentación y definición de nichos objetivo en los sectores y actividades económicas que atienden, para dar enfoque y viabilidad a la estrategia.
- Documentación y divulgación de casos de éxito de empresas nacionales en los diferentes sectores y actividades económicas, a partir de los cuales se puedan evidenciar las mejores prácticas que dirigen el desarrollo del mercado.

- Definición y uso de una metodología de prospección que facilite no sólo el diagnóstico del estado actual de la organización y del sector al que pertenece, sino los escenarios futuros más probables

Los anteriores aspectos, aunque difícilmente son una lista exhaustiva de la problemática de las empresas PYME ante su necesidad de innovar, permiten visualizar importantes retos que deben asumirse y barreras que deben superarse para hacer que el entorno interno y externo de las organizaciones favorezca su capacidad de producir y competir. Se percibe, como aspecto común de esta problemática, la necesidad de desarrollar capacidades de asimilación, adaptación y creación de conocimiento en diferentes aspectos, lo que permite la definición y aplicación de mecanismos efectivos de aprendizaje y de trayectorias viables de modernización empresarial. 


\section{BIBLIOGRAFÍA}

ARCE Sigifredo y CIFUENTES Jorge, «Gestión del Conocimiento: reseña sobre tendencias recientes a nivel mundial». Grupo de Investigación en Management. Vicerectoría de Investigaciones. Universidad EAN. Noviembre de 2006.

- BENAVIDES VELASCO, Carlos A. y QUINTANA GARCÍA, Cristina «Gestión del Conocimiento y Calidad Total» Ediciones Díaz de Santos S.A. y Asociación Española para la Calidad Madrid 2003.

- CASTELLANOS, Gonzalo. PyMES INNOVADORAS. Cambio de Estrategias e Instrumentos. REVISTA ESCUELA DE ADMINISTRACIÓN DE NEGOCIOS No. 47 ENERO - ABRIL DE 2003 Págs. 10 - 33.

- CHIESA, V.; COUGHLAN, P.; VOSSM C.A. Journal of Product Innovation Management, Volume 13, Number 2, March 1996

- DIAZ, Luz Victoria. "Gestión del Conocimiento y Tecnologías de Información y Comunicaciones». REVISTA ESCUELA DE ADMINISTRACIÓN DE NEGOCIOS No. 58 Septiembre a Diciembre de 2006. Págs. $41-59$.

. Informe final del Proyecto «RED-ET|». «Consolidación de la Red Especializada de Centros de Investigación y Desarrollo Tecnológico de Electrónica, Telecomunicaciones e Informática ETI.» Octubre de 2002.

o RED-ETI: Proyecto realizado por el Centro de Investigación de las Telecomunicaciones (CINTEL), Instituto Tecnológico de Electrónica y Comunicaciones (ITEC), Centro de Apoyo de la Tecnología Informática (CATI), Centro Internacional de Física (CIF), con el apoyo financiero de COLCIENCIAS, durante Septiembre de 2001 a Octubre de 2002. Gerente del Proyecto: Luz Victoria Díaz R.

. Conferencia de presentación de resultados del proyecto «RED-ETI». Retos y oportunidades de la industria de Electrónica, Telecomunicaciones e Informática (ETI) ante sectores estratégicos del desarrollo nacional. Octubre 7 de 2002.

. EDVINSON, 1997. «Developing Intellectual Capital at Skandia».

- ESCORSA, Pere (2003). Capítulo 1: «La Innovación en Tecnología e Innovación en la empresa. Ediciones UPC.

HALL, B. (2005). «Innovation and Difusión». Capítulo 17. The Oxford Handbook of Innovation. Oxford University Press. Oxford. 
- [HOUSEL, Thomas; BELL, Arthur H. 2001]. «Measuring and Managing Knowledge». Mc GrawHill Higher Education.

- HOWELLS, J.R.L. y y THETHER,, B.S. (2004). «Innovation in Services». Issues at stake and trends. A Report for the European Commission». Brussels.

- HUNT, S.D. (1983). Marketing Theory: The Philosophy of Marketing Science. Richard D. Irwin. Inc. New Cork.

- JENNEX, M. E. and OLFMAN, L. (2004). Modeling Knowledge Management Success. Conference on Information Science and Technology Management, CISTM.

- KLINE, Stephen J. Innovation is not a Linear Process/Stephen J Kline. Research Management, jul-ago, 1985

- LAM, A. (2005). «Organizacional Innovation». Capítulo 5. The Oxford Handbook of Innovation. Oxford University Press. Oxford.

- LUNDVALL, B-A. (ed) (1992), Nacional Systems of Innovation: Towards a Theory of Innovation and Interactive Learning, Pinter Publishers, London. Nelson R. (1993). National Innovation Systems, Oxford UP, Oxford.

- LLORIA ARAMBURO, Ma Begoña. «Diseño organizativo, facilitadores y creación de conocimiento. Un estudio empírico en las grandes empresas españolas». Tesis doctoral Universidad de Valencia. España 2004 [en línea] http://www.tdx.cesca.es/TDX-0125105132214/ Julio 20 de 2006.

- MAIER R. (2002). Knowledge Management Systems: Information and Communication Technologies for Knowledge Management. Berlin: Springer-Verlag.

- Manual de Oslo. Guía para la recogida e interpretación de datos sobre innovación. 3a. Edición. OCDE, Organización de Cooperación y Desarrollo Económicos. Oficina de Estadísticas de las Comunidades Europeas.

- Modelo Intellectus. Modelo desarrollado por el Instituto Universitario de Administración de Empresas de la Universidad Autónoma de Madrid, socializado dentro del Foro del Conocimiento Intellectus sobre Sociedad del Conocimiento, año 2002.

- MURRAY, E. Jennex, San Diego State University . «Knowledge Management Systems». www.management.com.ua

- MYERS y MARQUIS (1969). Myers, Sumner. Successful Commercial Innovations/ Sumner Myers y Donald Marquis. National Science Foundation. Washington, 1969. 
- NELSON R. y WINTER, S. (1982). An Evolutionary Theory of Economic Change, Belknap Press of Harvard University Press. Cambridge, Massachusetts.

- NIETO, Mauricio. Producción y gestión del conocimiento en la actividad académica. REVISTA ESCUELA DE ADMINISTRACIÓN DE NEGOCIOS No. 53 ENERO - ABRIL DE 2005 Págs. 36 -51 .

- ORDOÑEZ DE PABLOS, Patricia. «Las cuentas de Capital Intelectual como complemento del informe anual» En Revista Economía Industrial No. 357 [en línea] http://www.mityc/ MITycCMS/Templates/ListadoPublicacionesPorMateria.aspx Noviembre 19 de 2006.

- PEREZ, Rafael. «Liderazgo Visionario: centro del conocimiento». REVISTA ESCUELA DE ADMINISTRACIÓN DE NEGOCIOS No. 58 Septiembre a Diciembre de 2006. Págs. 79 - 85.

- Proyecto MERITUM (MEasuRing Intangibles To Understand and improve innovation Management). http://www.uam.es/meritum

- ROSEGGER, 1980. Citado por Castro (2001). Castro Díaz-Balart, Fidel. Ciencia, innovación y futuro/ Fidel Castro Díaz-Balart. Ediciones Especiales, Instituto Cubano del Libro, Habana 2001; 507p.

- STEWART, Thomas A. La Nueva Riqueza de las Organizaciones: el capital intelectual. (1991).

- SUTTON, J. 1992, Sunk Costs and Market Structure, MIT Press, Cambridge, Massachusets. Sutton, J. 1998. Technology and Market Structure, MIT Press, Cambridge, Massachusets.

. TIROLE, J. (1995). The Theory of Industrial Organization, MIT Press.

- UDAONDO, M. (2000). La gestión del Conocimiento. Documento electrónico: http:// www.gestiondel concomiento.com/documentos $2 /$ mudaondo/gdcon.htm

- VELASQUEZ, Andrés. «Diseño de Organizaciones para la Creación de Conocimiento». Revista EAN No. 58, Septiembre a Diciembre de 2006. Págs. 5 - 25.

. WUMAN, Richard . «Angustia informativa». Prentice Hall. Pearson Educación (2001) 
